\title{
МНОГОЛЕТНЯЯ ИЗМЕНЧИВОСТЬ ХИМИЧЕСКОГО СОСТАВА И КАЧЕСТВА ВОДЫ НА ВСЕМ ПРОТЯЖЕНИИ РЕКИ АМУР
}

\author{
Коваленко А. . $^{1,2}$ \\ ${ }^{1}$ Гидрохимический институт Росгидромета

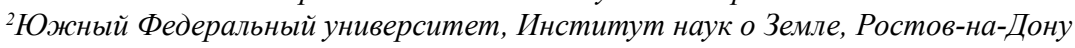 \\ arinaa.kov@gmail.com
}

Аннотация: В условиях антропогенного воздействия на окружающую среду и несбалансированного природопользования может происходить снижение самоочищающей способности реки Амур и ухудшение качества воды. Водопользование в бассейне реки осуществляется со стороны трёх государств: России, Монголии и Китая. Основными источниками поступления загрязняющих веществ в Амур с российской стороны являются предприятия деревообрабатывающей промышленности, машиностроение, цветная металлургия, добыча полезных ископаемых, производство электроэнергии. Снижение качества воды происходит также за счет недостаточной степени очистки сточных вод. Трансграничное положение изучаемого водного объекта, разница демографических потенциалов России и Китая и активное техногенное воздействие со стороны сопредельных территорий обусловливает актуальность настоящего исследования, целью которого является оценка многолетней изменчивости химического состава и качества воды на протяжении реки Амур. Исследование проведено на основе многолетних (2000-2017 гг.) гидрохимических данных Государственной системы наблюдений за состоянием и загрязнением окружающей среды Росгидромета в пунктах наблюдений на р. Амур: с. Черняево, гг. Благовещенск, Хабаровск, Комсомольск-на-Амуре и Николаевск-на-Амуре.

Рассмотрен химический состав воды на различных участках реки и проведена оценка качества воды по гидрохимическим показателям. Построены графики временной изменчивости значений удельного комбинаторного индекса загрязненности воды (УКИЗВ). Анализ многолетних данных показал, что на всех исследуемых участках реки концентрации хлоридов, сульфатов и нитратов не превышают предельно допустимые концентрации. Выявлены характерные загрязняющие вещества, содержание которых превышает нормативы ПДК более, чем в половине случаев. Это органические вещества, азот аммонийный, соединения железа, меди, цинка, никеля, марганца, фенолы и нефтепродукты. Наблюдается увеличение содержания некоторых загрязняющих веществ вниз по течению реки. В целом качество воды реки Амур на различных участках характеризуется 3-м («загрязненная» и «очень загрязненная») и 4-м классами качества («грязная»). В динамике выражена общая положительная тенденция незначительного снижения уровня загрязненности воды.

Ключевые слова: река Амур, химический состав, качество воды, степень загрязненности воды, гидрохимическая информация, антропогенное воздействие 


\title{
LONG-TERM VARIABILITY \\ OF CHEMICAL COMPOSITION AND QUALITY OF WATER ALONG THE AMUR RIVER
}

\author{
Kovalenko A.A. ${ }^{1,2}$ \\ ${ }^{1}$ Hydrochemical Institute of Roshydromet \\ ${ }^{2}$ Southern Federal University, Institute of Earth Science, Rostov-on-Don
}

\begin{abstract}
Annotation: The title of the article is long-term variability of chemical composition and quality of water along the Amur river. As the title implies the article describes the chemical composition of water in different parts of the river and the water quality by hydrochemical parameters. A mention should be made that under the conditions of anthropogenic press on the environment and unbalanced use of natural resources, the ecological potential of the water ecosystem of the Amur River is depleted and the quality of water decreases. The transboundary position of the studied water object, the difference in the demographic potentials of Russia and China determines the relevance of this paper. The purpose of the work is to assess the long-term variability of the chemical composition and water quality along the Amur River.

It should be noted that this research is based on long-term (2000-2017) Hydrochemical information. The state system of observers for the state and environmental pollution of Roshydromet at observation points along the river: c. Chernyaevo, the city of Blagoveshchensk, Khabarovsk, Komsomolsk-on-Amur and Nikolaevsk-on-Amur.

As a result, the analysis of long-term data showed that the concentrations of chlorides, sulphates and nitrates do not exceed the maximum permissible concentrations on all the studied river sections. Identified characteristic pollutants, the content of which exceeds the MPC standards in more than half of the cases. There is an increase in the content of some pollutants downstream of the river. In general, the water quality of the Amur River at different sites is characterized by the 3rd ("polluted" and "very polluted") and 4th quality classes ("dirty”).
\end{abstract}

Key words: Amur river, chemical composition, water quality, water pollution degree, hydrochemical information, anthropogenic impact

Река Амур является главной водной артерией Дальневосточного региона, а также одной из крупнейших рек в мире. Ее длина от слияния р. Шилка и Аргунь составляет 2824 км [2]. Бассейн данной реки расположен в Восточной Азии, на территории трех государств: России, Китая и Монголии.

В ранее проведенных для данного региона исследованиях [2, 3] отмечается что, с середины 90-х годов прошлого века произошло ухудшение качества воды в Амуре. Ранее факты ухудшения качества вод также наблюдались, однако носили преимущественно сезонный характер и не имели столь серьезных последствий. По мнению ряда 
авторов [1-5], основная причина экологического кризиса объясняется комплексом различных факторов, но главным из них является трансграничный перенос загрязняющих веществ крупными притоками реки Амур (особенно р. Сунгари). Стабильность речных экосистем снижается из-за несбалансированного водопользования в бассейне реки Амур, химического загрязнения воды, нарушения гидрологического режима за счет регулирования водного стока, судоходства, загрязнения водосборов притоков, что, в свою очередь, приводит к антропогенной трансформации их экологического состояния и ухудшению качества воды [3, 4].

Основными источниками негативного воздействия на качество воды реки Амур с российской стороны являются ведущие отрасли промышленности, сточные воды которых загрязняют реку (деревообрабатывающая промышленность, машиностроение, цветная металлургия, добыча полезных ископаемых, производство электроэнергии), а также недостаточная степень очистки сточных вод [7]. Что касается китайской стороны, то помимо промышленных стоков, влияющих на качество вод реки, большую роль играет разница демографической нагрузки: китайское население в приграничной зоне во многом превышает российское. Антропогенное развитие сопредельной китайской территории идет несравнимо активнее, чем в российском приграничье, а несовершенная форма очистки бытовых и промышленных стоков не поспевает за темпами экономического развития в Китае [1].

Всё выше сказанное и обусловливает актуальность настоящего исследования, целью которого является оценка многолетней изменчивости химического состава и качества воды по длине реки Амур.

\section{Материалы и методы исследования}

Исследование проведено на основе многолетних (2000-2017 гг.) гидрохимических данных Государственной системы наблюдений Росгидромета. Использованы данные о химическом составе и качестве воды р. Амур в пунктах наблюдений у с. Черняево, гг. Благовещенск, Хабаровск, Комсомольск-на-Амуре и Николаевск-на-Амуре (таблица 1).

При оценке качества вод рассчитывается удельный комбинаторный индекс загрязнения воды (УКИЗВ), значение которого определяется по частоте и кратности превышения ПДК по нескольким показателям. В соответствии со значением УКИЗВ устанавливается класс 
Пункты режимных наблюдений по длине реки Амур

\begin{tabular}{|l|c|c|}
\hline \multicolumn{1}{|c|}{$\begin{array}{c}\text { Пункт режимных } \\
\text { наблюдений }\end{array}$} & $\begin{array}{c}\text { Расстояние от устья, } \\
\text { км }\end{array}$ & $\begin{array}{c}\text { Площадь водосбора, } \\
\text { тыс. км }^{2}\end{array}$ \\
\hline с. Черняево & 2386 & 440 \\
\hline г. Благовещенск & 1941 & 493 \\
\hline г. Хабаровск & 966 & 1630 \\
\hline г. Комсомольск-на-Амуре & 614 & 1730 \\
\hline г. Николаевск-на-Амуре & 48 & 1850 \\
\hline
\end{tabular}

качества воды от 1 до 5 [6]. Для выявления тенденций изменения химического состава и качества воды по полученным данным были построены таблицы содержания химических веществ в воде и графики временной изменчивости значений УКИЗВ для каждого из исследуемых пунктов.

\section{Результаты исследования}

Формирование химического состава воды происходит под влиянием природных и антропогенных факторов. К природным факторам относятся физико-географические (рельеф, климат, почвенный покров), геологические (состав горных пород, тектоническое строение, гидрогеологические условия), физико-химические (химические свойства элементов, окислительно-восстановительные и кислотно-щелочные условия, катионный обмен) и биологические факторы (деятельность растений и живых организмов) [2].

Помимо этого, химический состав р. Амур формируется под влиянием промышленных и хозяйственно-бытовых сточных вод береговых городов и поселков. Не исключено влияние трансграничного водного объекта - р. Сунгари, водосбор которой полностью находится на территории Китайской народной Республики и соответственно формирование гидрохимического состава реки происходит под влиянием сброса сточных вод промышленных предприятий и населенных пунктов КНР, а также поверхностного стока с территории, активно используемой сельскохозяйственными предприятиями КНР [2].

Для описания химического состава р. Амур в работе используются такие систематические характеристики, как среднемноголетние, минимальные и максимальные концентрации в каждом пункте наблюдений по длине реки. 
В таблице 2 дана характеристика химического состава воды реки Амур за многолетний период. Полученные концентрации сравнивались с предельно допустимой концентрацией для водоемов рыбохозяйственного назначения. Значения, превышающие ПДК лены красным цветом.

На основании табличных данных можно сделать следующие выводы:

- на всех исследуемых участках реки концентрации растворенного кислорода, хлоридов, сульфатов и нитратов не превышают ПДК

- наибольшая кратность превышения ПДК наблюдается по соединениям железа, марганца и меди;

- характерные загрязняющие вещества, содержание которых часто превышает нормативы ПДК, - это органические вещества (определяемые по показателям химическое потребление кислорода (ХПК) и биохимическое потребление кислорода $\left(Б \mathrm{~K}_{5}\right)$ ), аммонийный азот, железо, медь, цинк, никель, марганец, фенолы, нефтепродукты.

- происходит увеличение содержания отдельных загрязняющих веществ в водной среде вниз по течению реки: так среднемноголетняя концентрация железа у с. Черняева (2386 км от устья) составляет 0,31 мг/дм³ , а в устье реки ниже г. Николаевск-на-Амуре - 0,62 мг/дм³.

Периодическое накопление в водной среде перечисленных выше загрязняющих веществ может приводить к повышению степени загрязненности и ухудшению качества воды на исследуемых участках трансграничного объекта. В целом качество воды реки Амур на различных участках характеризуется 3-м («загрязненная» и «очень загрязненная») и 4-м классами качества («грязная»).

Анализ многолетних данных об изменчивости значений УКИЗВ позволил выявить основные тенденции пространственно-временной динамики качества воды по длине реки Амур.

В верхней части реки, выше с. Черняево, наблюдается тенденция повышения значений УКИЗВ, что соответствует незначительному ухудшению качества воды на данном участке реки (рисунок 1а). В целом качество воды соответствует 3-му («загрязненная» и «очень загрязненная») и 4-му классам качества («грязная»).

Ниже г. Благовещенск наблюдается тенденция снижения значений УКИЗВ (рисунок 1б), которая соответствует улучшению состояния качества воды. За исследуемый период можно отметить переход 
Таблица 2

\section{Содержание химических веществ (в мг/дм³) в воде реки Амур за многолетний период (2000-2017 гг.)}

\begin{tabular}{|c|c|c|c|c|c|}
\hline \multirow{2}{*}{$\begin{array}{l}\text { Химическое } \\
\text { вещество }\end{array}$} & с. Черняево & $\begin{array}{l}\text { г. Благове- } \\
\text { щенск }\end{array}$ & г. Хабаровск & $\begin{array}{c}\text { г. Комсо- } \\
\text { мольск }\end{array}$ & г. Николаевск \\
\hline & выше села & ниже города & ниже города & ниже города & ниже города \\
\hline Кислород & $\frac{7,88-13,64 *}{10,77}$ & $\frac{7,03-11,48}{8,90}$ & $\frac{6,87-14,46}{10,30}$ & $\frac{6,51-11,89}{9,00}$ & $\frac{7,35-13,57}{10,41}$ \\
\hline Хлориды & $\frac{2,29-8,96}{4,64}$ & $\frac{1,90-6,68}{3,39}$ & $\frac{2,13-7,19}{3,99}$ & $\frac{1,70-7,33}{3,73}$ & $\frac{1,72-11,23}{4,56}$ \\
\hline Сульфаты & $\frac{6,24-18,67}{11,41}$ & $\frac{3,70-15,56}{7,74}$ & $\frac{6,49-37,81}{17,07}$ & $\frac{5,20-27,91}{14,55}$ & $\frac{3,36-31,25}{14,34}$ \\
\hline $\begin{array}{l}\text { Органическое } \\
\text { вещество (по } \\
\text { ХПК) } \\
\end{array}$ & $\frac{12,04-36,91}{21,86}$ & $\frac{11,29-34,84}{20,69}$ & $\frac{5,62-34,29}{17,04}$ & $\frac{8,85-36,42}{19,42}$ & $\frac{7,58-39,32}{19,71}$ \\
\hline $\begin{array}{l}\text { Легкоокисляе- } \\
\text { мые органиче- } \\
\text { ские вещества } \\
\text { (по БПК })\end{array}$ & $\frac{0,93-2,01}{1,41}$ & $\frac{0,98-2,38}{1,55}$ & $\frac{1,21-3,48}{2,11}$ & $\frac{1,11-3,09}{1,89}$ & $\frac{0,83-3,17}{1,67}$ \\
\hline $\mathrm{NH}_{4}^{+}$ & $\frac{0,18-0,98}{0,48}$ & $\frac{0,17-1,23}{0,52}$ & $\frac{0,13-1,20}{0,46}$ & $\frac{0,31-1,15}{0,67}$ & $\frac{0,16-1,13}{0,49}$ \\
\hline $\mathrm{NO}_{2}^{-}$ & $\frac{0,003-0,017}{0,008}$ & $\frac{0,008-0,020}{0,010}$ & $\frac{0,003-0,034}{0,011}$ & $\frac{0,004-0,045}{0,016}$ & $\frac{0,004-0,048}{0,015}$ \\
\hline $\mathrm{NO}_{3}^{-}$ & $\frac{0,08-0,66}{0,26}$ & $\frac{0,05-0,63}{0,19}$ & $\frac{0,09-1,01}{0,38}$ & $\frac{0,13-0,80}{0,35}$ & $\frac{0,10-0,75}{0,36}$ \\
\hline $\mathrm{Fe}$ & $\frac{0,10-0,70}{0,31}$ & $\frac{0,13-0,64}{0,33}$ & $\frac{0,20-0,94}{0,46}$ & $\frac{0,22-1,03}{0,55}$ & $\frac{0,30-1,12}{0,62}$ \\
\hline $\mathrm{Cu}^{* *}$ & $\frac{1,89-5,89}{3,63}$ & $\frac{1,39-9,23}{3,78}$ & $\frac{0,14-12,18}{3,72}$ & $\frac{0,80-21,48}{7,67}$ & $\frac{0,12-17,81}{4,62}$ \\
\hline $\mathrm{Zn} * *$ & $\frac{4,93-28,17}{12,20}$ & $\frac{4,22-26,29}{10,90}$ & $\frac{0,83-35,93}{9,99}$ & $\frac{2.83-39,05}{16,32}$ & $\frac{0,18-129,6}{23,99}$ \\
\hline $\mathrm{Ni}^{* *}$ & $\frac{1,64-12,65}{6,69}$ & $\frac{0,82-20,09}{5,75}$ & $\frac{0,38-9,57}{3,67}$ & $\frac{0,05-17,81}{5,86}$ & $\frac{0,73-25,11}{6,65}$ \\
\hline $\mathrm{Mn}^{* *}$ & $\frac{80,2-206,2}{130,4}$ & $\frac{65,3-169,4}{105,1}$ & $\frac{51,6-191,5}{108,9}$ & $\frac{58,7-278,5}{138,4}$ & нет данных \\
\hline Фенолы & $\frac{0,002-0,006}{0,004}$ & \begin{tabular}{|c|}
$\frac{0,001-0,005}{0,002}$ \\
\end{tabular} & $\frac{0,000-0,007}{0,002}$ & $\frac{0,000-0,008}{0,003}$ & $\frac{0,000-0,012}{0,004}$ \\
\hline $\begin{array}{l}\text { Нефтепро- } \\
\text { дукты }\end{array}$ & $\frac{0,02-0,07}{0,04}$ & $\frac{0,01-0,10}{0,04}$ & $\frac{0,00-0,26}{0,04}$ & $\frac{0,00-0,19}{0,05}$ & $\frac{0,00-0,45}{0,06}$ \\
\hline
\end{tabular}

из 4-го класса разряд «а» («грязная») в 3-й класс качества разряд «б» («очень загрязненная»).

На участке ниже г. Хабаровск (рисунок 1в) наблюдается четкая тенденция снижения значений УКИЗВ, которая соответствует улуч- 

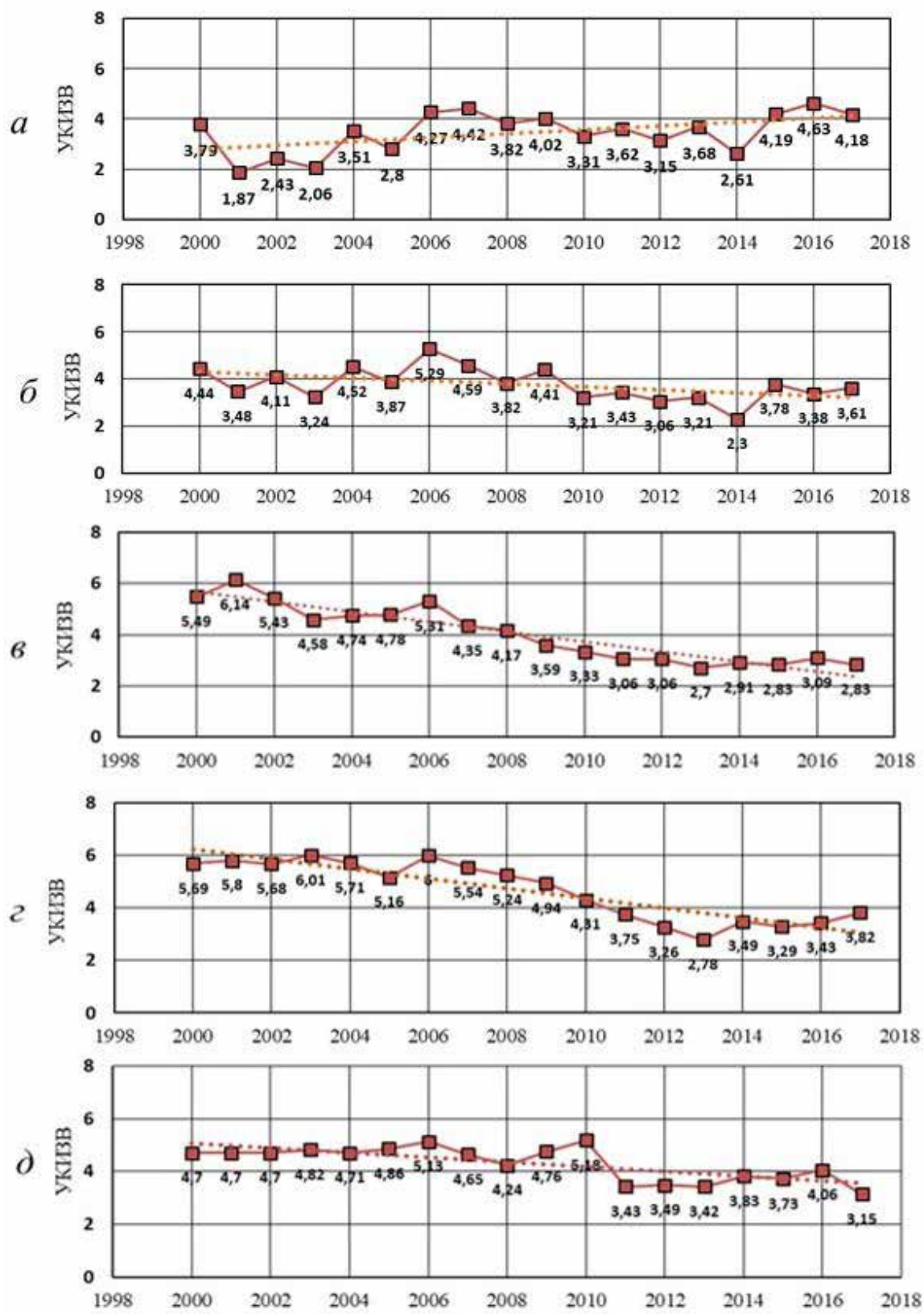

Рис. 1. Временная изменчивость значений УКИЗВ в р. Амур на участках выше с. Черняево (а), ниже гг. Благовещенск (б), Хабаровск (в), Комсомольск-на-Амуре (г) и ниже г. Николаевск-на-Амуре (д) 
шению качества речной воды. Отмечается снижение степени загрязненности воды от категории «грязная» (4-й класс) до «загрязненная» (3-й класс качества воды). Далее ниже по течению сохраняется общая тенденция улучшения качества воды (переход из класса 4 «а» в 3 «б») в районе гг. Комсомольск-на-Амуре (рисунок 1г) и Николаевск-на-Амуре (рисунок 1д).

На начало периода исследования (2000 год) качество воды в реке Амур в целом соответствовало 4 «а» классу качества воды (степень загрязненности - «грязная»), только в пункте с. Черняево класс качества воды соответствовал 3 «б» классу качества («очень загрязненная»). Характерными загрязняющими веществами являлись фенолы, соединения марганца, меди и железа (рисунок 2a).

К 2017 году, в большинстве пунктов наблюдается улучшение состояния водных систем и переход воды из класса 4 «а» («грязная») в 3 «а» («загрязненная») и 3 «б» («очень загрязненная») (рисунок 2б). Однако, в с. Черняево отмечается ухудшение качества воды и переход из класса 3 «б» («очень загрязненная») в 4 «а» («грязная»). Перечень характерных загрязняющих веществ для р. Амур в 2017 году составили соединения металлов - меди, марганца и железа.

\section{Заключение}

Анализ многолетних гидрохимических данных показал, что на всех исследуемых участках реки концентрации хлоридов, сульфатов и нитратов не превышают предельно допустимые концентрации. Выявлены характерные загрязняющие вещества, содержание которых часто превышает нормативы ПДК, - это органические вещества (по ХПК и БПК ${ }_{5}$ ), аммонийный азот, железо, медь, цинк, никель, марганец, фенолы, нефтепродукты.

В целом качество воды реки Амур на различных участках характеризуется 3-м («загрязненная» и «очень загрязненная») и 4-м классами качества («грязная»). В динамике выявлена общая тенденция улучшения качества воды с 4-го на 3-й класс качества, кроме верхнего течения (с. Черняево).

Следует отметить, что выявленная положительная тенденция снижения уровня загрязненности воды р. Амур может быть связана с усилением контроля за сточными водами, особенно на трансграничных участках, проведением водоохранных мероприятий по улучшению качества воды в бассейне р. Амур в рамках Федеральной целевой про- 

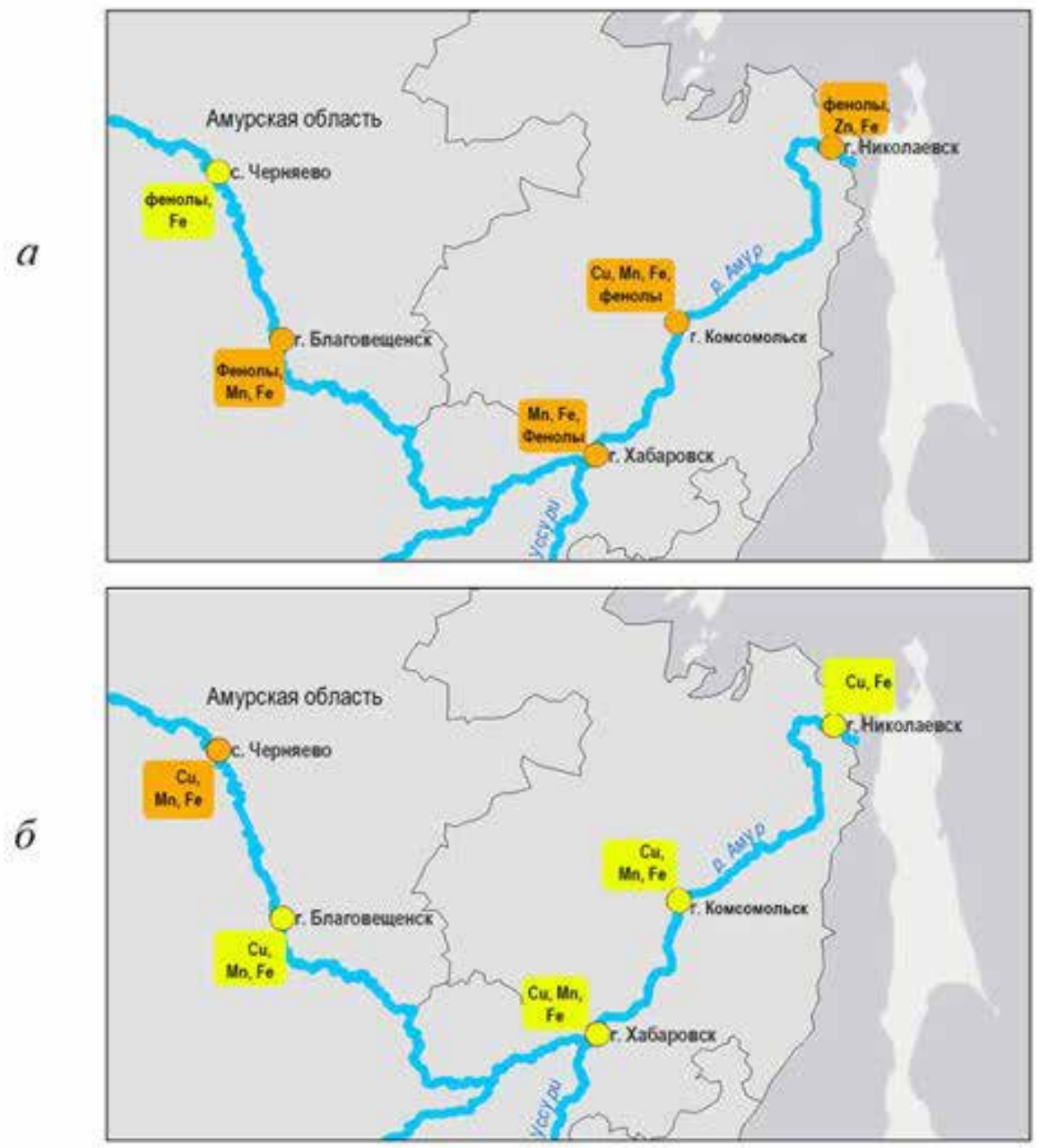

Рис. 2. Качество воды и характерные загрязняющие вещества по длине реки Амур в 2000 (а) и в 2017 (б) годах (Обозначения: желтый цвет соответствует 3 классу качества воды, оранжевый - 4 классу качества воды; в прямоугольниках вынесены характерные загрязняющие вещества)

граммы «Развитие водохозяйственного комплекса РФ в 2012-2020 годах», приоритетными направлениями которой являются сохранение и восстановление водных объектов на основе снижения антропогенной нагрузки на них; предотвращение негативного воздействия вод и повышение рациональности использования водных ресурсов. Проблема химического загрязнения водосбора трансграничной реки Амур се- 
годня особенно актуальна и требует постоянного мониторинга и контроля качества воды.

Научный руководитель: дочуент, с.н.с. ФГБУ «ГХИ», к.г.н. Решетняк О.С.

\section{Литература}

1. Голобокова Я.А. Экологические проблемы бассейна реки Амур // Власть 2008. - №3 - С.105-107.

2. Никаноров А.М., Брызгало В.А. Реки России. Часть IV. Реки Дальнего Востока (гидрохимия и гидроэкология): монография. - Ростов/Д: «НОК», 2011. - 324 с.

3. Никаноров А.М., Брызгало В.А., Косменко Л.С., Решетняк О.С. Антропогенная трансформация экологического состояния речных экосистем Дальнего Востока // Вода: химия и экология, № 3. 2012. С.10-20.

4. Никаноров А.М., Брызгало В.А., Решетняк О.С., Косменко Л.С., Даниленко А.О. Антропогенная трансформация экологического состояния и транспорт загрязняющих веществ по длине реки Амур // Водное хозяйство России: проблемы, технологии, управление. № 5, 2013. С.15-26.

5. Решетняк О.С., Даниленко А.О. Многолетняя динамика изменчивости компонентного состава водной среды устьевой области р. Амур // Водные ресурсы, экология и гидрологическая безопасность: сборник трудов Четвертой международной научной конференции молодых ученых и талантливых студентов / Отв. ред. Н.Н.Митина - М.: ИВП РАН, 2010. - С. 215-218.

6. РД 52.24.643-2002. Метод комплексной оценки степени загрязненности поверхностных вод по гидрохимическим показателям [Текст]. - Введ. 03-12-2002. - М.: Ростов-на-Дону, 2002. - 55 с.

7. Отчет о выполнении работ для государственных нужд «Доработка проекта СКИОВО по бассейну реки Амур». Государственный контракт № 15 от 26 июня 2012 г. Книга 1. Общая характеристика бассейна р.Амур. Екатеринбург, 2012.

\section{Reference}

1. Golobokova Ya.A. Ecological problems of the Amur River basin // Power - 2008. - №3 - pp.105-107.

2. Nikanorov A.M., Bryzgalo V.A. Rivers of Russia. Part IV. Rivers of the Far East (hydrochemistry and hydroecology): monograph. - Rostov / D: "NOC", 2011. - 324 p.

3. Nikanorov A.M., Bryzgalo V.A., Kosmenko L.S., Reshetnyak O.S. Anthropogenic transformation of the ecological state of the river ecosystems of the Far East // Water: chemistry and ecology, No. 3. 2012. pp.10-20.

4. Nikanorov A.M., Bryzgalo V.A., Reshetnyak O.S., Kosmenko L.S., Danilenko A.O. Anthropogenic transformation of the ecological state and transport of pollutants along the length of the Amur River // Water Industry of Russia: problems, technologies, management. Number 5, 2013. pp.15-26.

5. Reshetnyak O.S., Danilenko A.O. The long-term dynamics of the variability of the composition of the aquatic environment of the mouth area p. Amur // Water Resources, 
Ecology and Hydrological Safety: Collected Works of the Fourth International Scientific Conference of Young Scientists and Talented Students / Ed. ed. NN Mitina - M .: IWP RAS, 2010. - pp. 215-218.

6. RD 52.24.643-2002. The method of integrated assessment of the degree of contamination of surface waters by hydrochemical parameters [Text]. - Enter 03-12-2002. - M .: Rostov-on-Don, 2002. - 55 p.

7. Report on the performance of work for state needs "Finalization of the SKIOVO project on the Amur River basin". State contract number 15 of June 26, 2012 Book 1. General characteristics of the Amur river basin. Ekaterinburg, 2012. 